\title{
Bioavailability and Safety of a New Highly Concentrated Midazolam Nasal Spray Compared to Buccal and Intravenous Midazolam Treatment in Chinese Healthy Volunteers
}

\author{
Hui Wang · Jie Huang · Shuang Yang · Xing-fei Zhang · Xiaoyan Yang • \\ Chang Cui · Chan Zou · Li-e Li · Min Zhang • Miao-fu Mao • \\ Xiang Zhou $\cdot$ Kai-ming Duan $\cdot$ Sai-ying Wang $\cdot$ Guo-ping Yang (D)
}

Received: December 4, 2021 / Accepted: January 20, 2022 / Published online: February 7, 2022

(C) The Author(s) 2022

\begin{abstract}
Introduction: Buccal midazolam treatment is licensed in the European Union for prolonged acute convulsive seizures in children and adolescents, but the buccal pathway is often hampered by jaw clenching, hypersalivation, or uncontrolled swallowing. Midazolam formulations that are more secure, reliable, and faster for use are needed in the acute setting. Pharmacokinetics and comparative bioavailability of intranasally administered midazolam and two midazolam intravenous solutions administered buccally or intravenously in healthy adults were evaluated.
\end{abstract}

Hui Wang and Jie Huang contributed equally to this work.

H. Wang - J. Huang $\cdot$ S. Yang - X. Zhang - X. Yang .

C. Cui · C. Zou · G. Yang (凶)

Center for Clinical Pharmacology, The Third

Xiangya Hospital, Central South University,

Changsha 410013, Hunan, China

e-mail: ygp9880@126.com

K. Duan · S. Wang ( $₫)$

Department of Anesthesiology, The Third Xiangya

Hospital, Central South University, Changsha

410013, Hunan, China

e-mail: 1771303488@qq.com

L. Li - M. Zhang - M. Mao - X. Zhou

Yichang Renfu Pharmaceutical Co., Ltd., Yichang

443000, Hubei, China
Methods: In this phase 1, open-label, randomized, single-dose, three-period, three-sequence crossover study, 12 healthy adults (19-41 years) were randomly assigned to receive $2.5 \mathrm{mg}$ midazolam intranasally; $2.5 \mathrm{mg}$ midazolam intravenously; $2.5 \mathrm{mg}$ midazolam buccally. Blood samples were collected for $10 \mathrm{~h}$ post dose to determine pharmacokinetic profiles. Adverse events and vital signs were recorded.

Results: Intranasal administration of $2.5 \mathrm{mg}$ midazolam demonstrated a more rapid median time to $C_{\max }$ compared to buccal administration of midazolam ( $T_{\max }, 12.6 \mathrm{~min}$ vs. $45 \mathrm{~min}$; $C_{\max }, \quad 38.33 \mathrm{ng} / \mathrm{ml}$ vs. $\left.24.97 \mathrm{ng} / \mathrm{ml}\right)$. The antiepileptic effect of intranasal and buccal midazolam treatment lasted less than $4 \mathrm{~h}$ and generally did not differ from intravenously administered midazolam. No serious adverse events or deaths were reported, and no treatment-emergent adverse events led to study discontinuation.

Conclusion: Intranasal administration of midazolam may be a preferable alternative to the currently approve buccal midazolam treatment for prolonged acute convulsive seizures in children and adolescents.

Trial Registration: This study is registered at the Chinese Clinical Trial [http://www.chictr. org.cn] (ChiCTR2000032595) on 3 May, 2020.

Keywords: Midazolam; Bioavailability; Safety; Nasal spray; Intravenous midazolam
Buccal midazolam; 


\section{Key Summary Points}

\section{Why carry out this study?}

It is well established that timely and rapid treatment for epileptic seizures is critical.

Buccal midazolam treatment (2.5-10 mg) was licensed in the European Union, but the buccal route of administration is often hampered by jaw clenching, hypersalivation, or uncontrolled swallowing. Then a nasal spray was developed for midazolam and approved by US Food and Drug Administration (FDA) in 2019.

A novel concentrated midazolam nasal spray was developed by Yichang Renfu Pharmaceutical Co., Ltd in China. Considering the lack of studies comparing the pharmacokinetics and bioavailability of intranasal, buccal, and intravenous administration of midazolam, the objective of this study was to evaluate these parameters in healthy volunteers.

\section{What was learned from the study?}

The results from this phase 1 study confirm that midazolam is quickly and consistently absorbed by intranasal compared with buccal administration $\left(T_{\max }, 12.6 \mathrm{~min}\right.$ vs. $45 \mathrm{~min} ; C_{\max }$, $38.33 \mathrm{ng} / \mathrm{ml}$ vs. $24.97 \mathrm{ng} / \mathrm{ml}$ ) at $2.5 \mathrm{mg}$ dose, but intranasal midazolam administration has a relatively lower plasma $\mathrm{AUC}_{0-\infty}$ than buccal midazolam $\left(\mathrm{AUC}_{0-\infty}, 77.20\right.$ vs. $\left.95.90 \mathrm{ng} \cdot \mathrm{h} / \mathrm{ml}\right)$.

Intranasal midazolam administration could be a preferable alternative to buccal midazolam administration for the treatment of prolonged acute convulsive seizures in children and adolescents.

\section{INTRODUCTION}

Epilepsy is a chronic brain disorder characterized by an enduring predisposition to generate seizures [1]. At presents, 3.4 million people in the USA and 10 million people in China are suffering from epilepsy [2, 3], among which $50 \%$ of patients started epilepsy in childhood [4]. Repeated and lasting epileptic seizure in the most severe form of epilepsy-status epilepticus, which causes life-threatening emergencies and is associated with a higher mortality rate [5]. Prompt emergency interventions with rapid delivery of antiepileptic drugs to the brain have been proved effective for the rapid termination of seizures [6].

Benzodiazepines (diazepam and midazolam) are the most commonly used, first-line drugs for the management of acute seizures $[4,7,8]$. Buccally administered midazolam (BC-MDZ) and rectally administered diazepam are recommended for treating seizure clusters in several authoritative guidelines in China, and they are licensed in the European Union [9, 10]. As a result of the disadvantage of inconvenient use of the rectal preparation [10] and the buccal route of administration often being hampered by jaw clenching, hypersalivation, or uncontrolled swallowing [11], which limits their use in the acute setting [12], a nasal spray was developed for both drugs and approved by the US Food and Drug Administration (FDA) in 2019 and 2020, respectively [9]. The FDA reported that midazolam nasal spray presented improved bioavailability compared with intranasal delivery of midazolam formulation intended for intravenous delivery; however, there is a lack of randomized controlled trials (RCT) directly comparing the bioavailability of intranasally administered midazolam (IN-MDZ) with BC-MDZ [13]. Studies comparing IN-MDZ with BC-MDZ are therefore warranted [10, 14], especially in the Chinese population.

Here, we performed a randomized phase 1 clinical trial in 12 healthy subjects to investigate the pharmacokinetics and safety of a novel concentrated midazolam nasal spray developed by Yichang Renfu Pharmaceutical Co., Ltd. The objective was to evaluate the bioavailability of a 
single dose of IN-MDZ $25 \mathrm{mg} / \mathrm{ml}$ (2.5 mg/puff) compared with $2.5 \mathrm{mg}$ intravenously administered midazolam (IV-MDZ) and BC-MDZ.

\section{METHODS}

\section{Ethics Statements}

This study was reviewed and approved by the Institutional Review Board of the Third Xiangya Hospital of Central South University (application number 2019116). The study was conducted in accordance with the Declaration of Helsinki and Good Clinical Practice guidelines. All subjects provided written informed consent and the study was registered at the Chinese Clinical Trial Registry [http://www.chictr.org. cn] (no. ChiCTR1900025071).

\section{Participants}

Eligible subjects were recruited according to the listed criteria: healthy adults (age greater than 18 years), male weight greater than $55.0 \mathrm{~kg}$, female weight greater than $45.0 \mathrm{~kg}$, with a body mass index (BMI) between 19.0 and $26.0 \mathrm{~kg} / \mathrm{m}^{2}$. Exclusion criteria were an abnormal anatomical structure of the nasal cavity, nasal or oral mucosa injury, excessive secretion of the nasal or oral mucosa and taste sensitivity, history of drug sensitivity, taken any drugs within 14 days or taken any drugs which can interfere with the metabolism of midazolam within 30 days before the study, especially CYP3A inhibitors, which can affect the pharmacokinetics of midazolam and prolong its sedative effect, participants who were alcoholic or smokers, drug dependent within the last 12 months, history of surgery within the last month, blood donation in the last 3 months, pregnancy or breast-feeding. Subjects with a difficult airway, including modified Mallampati grade III-IV, congenitial mouth and tongue enlargement, and mandibular dysplasia were excluded.

\section{Study Design}

This was a phase 1 , randomized, single-center, open-label, three-period, three-treatment crossover study to evaluate the bioavailability of a single dose of $2.5 \mathrm{mg}$ IN-MDZ compared with $2.5 \mathrm{mg}$ IV-MDZ and BC-MDZ. Twelve healthy adults were enrolled and each subject was randomized to receive one of the three potential treatments in sequence: IN-MDZ $(2.5 \mathrm{mg}), \mathrm{IV}$ MDZ (2.5 mg), or BC-MDZ (2.5 mg) (Fig. 1). Each subject got all three treatments in different periods and each treatment period was separated by a 7-day washout period. For IN-MDZ, a single actuation in one nostril was adopted. For IV-MDZ, midazolam intravenous solution (2 ml:10 mg, Yichang Renfu Pharmaceutical Co., Ltd.) was diluted to a final concentration of $2.5 \mathrm{mg}$ in a total volume of $10 \mathrm{ml}$ with $0.9 \%$ sodium chloride and injected intravenously within $1 \mathrm{~min}$. For BC-MDZ, a syringe was used to extract $0.5 \mathrm{ml} \mathrm{MDZ} \mathrm{injection}(2 \mathrm{ml}: 10 \mathrm{mg}$, Yichang Renfu Pharmaceutical Co., Ltd.). The full amount of solution should be inserted into the space between the gum and cheek (buccal cavity).

\section{Pharmacokinetic Measures}

Blood samples were collected for pharmacokinetic assessments at predose, and $0,1,3,5,10$, $15,20,30,45 \mathrm{~min}$ and 1, 1.5, 2, 3, 6, $10 \mathrm{~h}$ postdose. Plasma concentrations of midazolam and its major metabolite, $\alpha$-hydroxymidazolam (1-OH MDZ), were determined by reverse-phase high-performance liquid chromatography with tandem mass spectroscopy (HPLC-MS/MS) using the AB SCIEX QTRAP ${ }^{\circledR}$ 5500. The lower limit of quantification was $0.2 \mathrm{ng} / \mathrm{ml}$ and $0.04 \mathrm{ng} / \mathrm{ml}$, respectively. The assay was linear for midazolam from 0.2 to $120 \mathrm{ng} / \mathrm{ml}$ and 0.04 to $24 \mathrm{ng} / \mathrm{ml}$ for $1-\mathrm{OH} \mathrm{MDZ}$. The coefficient of variation $(\mathrm{CV})$ for this assay was $3.8-8.3 \%$.

\section{Pharmacokinetic Analyses}

Pharmacokinetic parameters were calculated using noncompartmental methods (WinNonlin Professional, version 8.1; Pharsight 


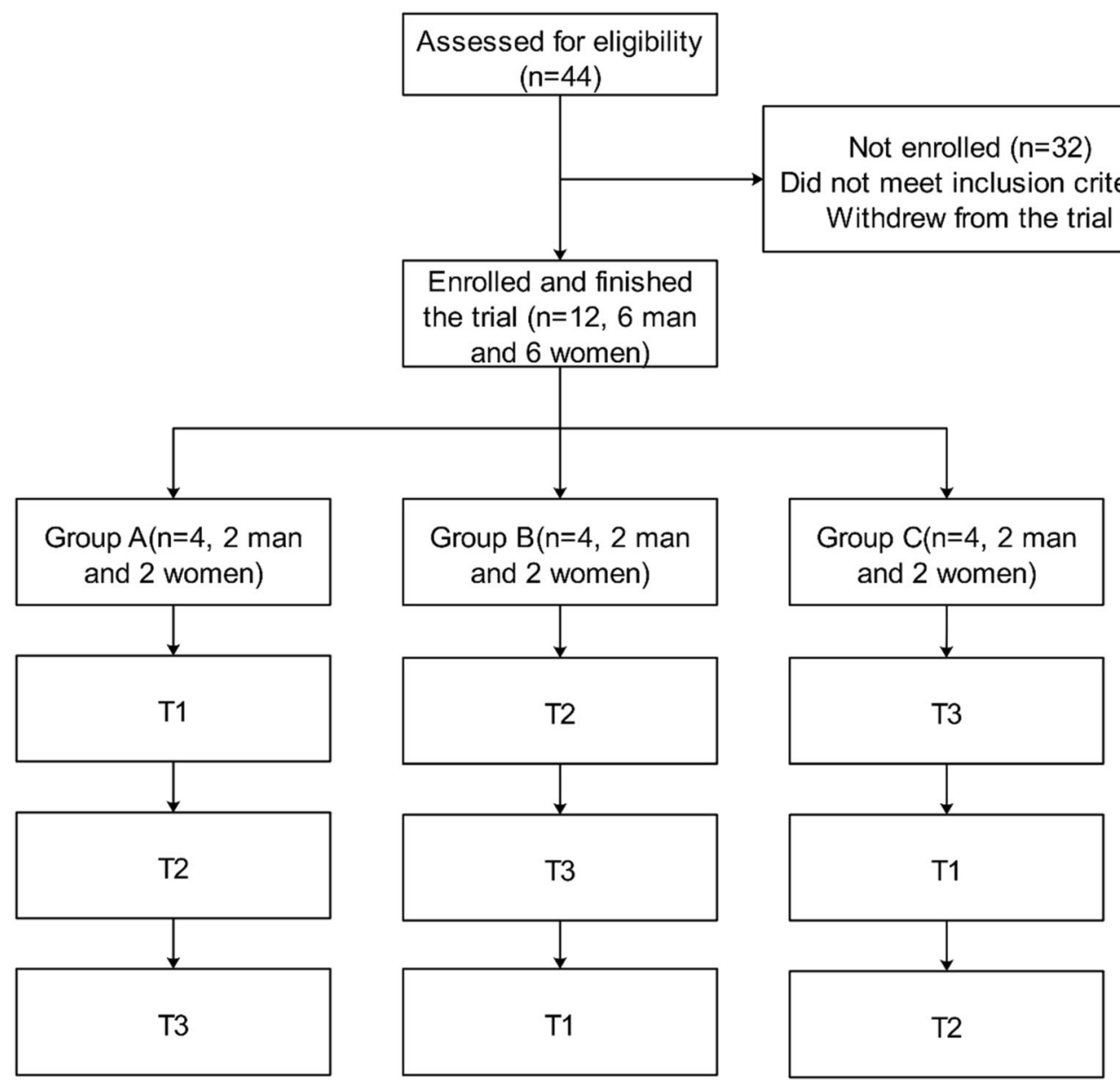

Fig. 1 Flowchart of the midazolam phase 1 trial study. T1: IV-MDZ $2.5 \mathrm{mg}$, slow intravenous injection in $1 \mathrm{~min}$; T2: IN-MDZ $2.5 \mathrm{mg}$, unilateral nostril administration once; T3: BC-MDZ $2.5 \mathrm{mg}$, one side of buccal

Corporation, Cary, NC, USA) and included area under the plasma concentration-time curve from time zero to the last measurable time point $\left(\mathrm{AUC}_{0-t}\right)$ and from time zero to infinity $\left(\mathrm{AUC}_{0-\infty}\right)$, terminal elimination half-life $\left(t_{1 / 2}\right)$, peak plasma concentration $\left(C_{\max }\right)$, and the time to reach maximum plasma concentration $\left(T_{\max }\right)$. Both absolute (ratio of $\mathrm{AUC}_{0-\infty}$ for IN$\mathrm{MDZ}$ or BC-MDZ to IV-MDZ) and relative (ratio of $\mathrm{AUC}_{0-\infty}$ for IN-MDZ to BC-MDZ) bioavailability of MDZ and 1-OH MDZ were determined, with the comparator value set at $100 \%$.

To evaluate pharmacokinetics between INMDZ $2.5 \mathrm{mg}$ and IV-MDZ $2.5 \mathrm{mg}$, an analysis of variance (ANOVA) with fixed effect (sequence, administration. Each subject got all three treatments in different periods and each treatment period was separated by a 7-day washout period

treatment, and period) and random effect (participant nested within the sequence) was performed on $\log$-transformed $C_{\max }$ data to obtain the geometric least-squares mean (GLSM) for each treatment. The ratio of GLSM between the IN-MDZ $2.5 \mathrm{mg}$ and IV-MDZ $2.5 \mathrm{mg}$ was calculated.

\section{Safety Assessments}

The safety was assessed on the basis of the vital signs, clinical laboratory tests, electrocardiogram, and physical examination during the study period. Drug-related AEs were determined by the principal investigator and clinicians. 
The severity of adverse events (AEs) was graded according to common terminology criteria for adverse events (CTCAE) version 5.0. The causality of AEs was evaluated as five categories: unrelated, unlikely, possibly, probably, or definitely related.

\section{RESULTS}

\section{Subjects Demographics}

Twelve Chinese healthy adults were enrolled in the study. The mean age of the study population was 27.6 years (range 19-41 years). The mean (SD) weight of the participants was $58.35 \pm 5.692 \mathrm{~kg}$. All participants completed the study and were included in the pharmacokinetic and safety evaluation.

\section{Pharmacokinetic Profiles}

Pharmacokinetic Profiles of Midazolam and $\alpha$ Hydroxymidazolam (1-OH MDZ)

Mean plasma concentration-time curves for midazolam and 1-OH MDZ after the three treatments are presented in Figs. 2 and 3. Pharmacokinetic parameters are summarized in Table 1 . The $T_{\max }$ values of IN-MDZ, IV-MDZ, or BC-MDZ were $12.6 \mathrm{~min}, 3 \mathrm{~min}$, and $45 \mathrm{~min}$, respectively, thereby demonstrating a rapid time to peak midazolam concentration (Table 1). The mean half-life was similar and ranged from 2.68 to $3.19 \mathrm{~h}$ (Table 1 ). The $C_{\max }$ of IN-MDZ and BC-MDZ was $38.33 \pm 18.55 \mathrm{ng} /$ $\mathrm{ml}$ and $24.97 \pm 4.99 \mathrm{ng} / \mathrm{ml}$.

$1-\mathrm{OH} \mathrm{MDZ}$ is the main hydroxylated metabolite of MDZ, representing $40-100 \%$ of unchanged drug [15]. As with the parent midazolam compound, the $\mathrm{AUC}_{\mathrm{O}_{-}}$and $C_{\max }$ of 1-OH MDZ levels are shown in Table 1.

\section{Bioavailability and Pharmacokinetic Equivalence}

The calculation of bioavailability is presented in Table 2 . The absolute bioavailability was $68.22 \%$ for BC-MDZ ( $\mathrm{AUC}_{0-\infty}$ of BC-MDZ vs. IV-MDZ, $95.8 \mathrm{ng} \cdot \mathrm{h} / \mathrm{ml}$ vs. $139.94 \mathrm{ng} \cdot \mathrm{h} / \mathrm{ml}$ ) and $49.39 \%$ for IN-MDZ (AUC ${ }_{0-\infty}$ of BC-MDZ vs. IV-MDZ $\mathrm{AUC}_{0-\infty}, 77.20 \mathrm{ng} \cdot \mathrm{h} / \mathrm{ml}$ vs. $\left.139.94 \mathrm{ng} \cdot \mathrm{h} / \mathrm{ml}\right)$. At the same dose of $2.5 \mathrm{mg}$, IN-MDZ and BC-MDZ

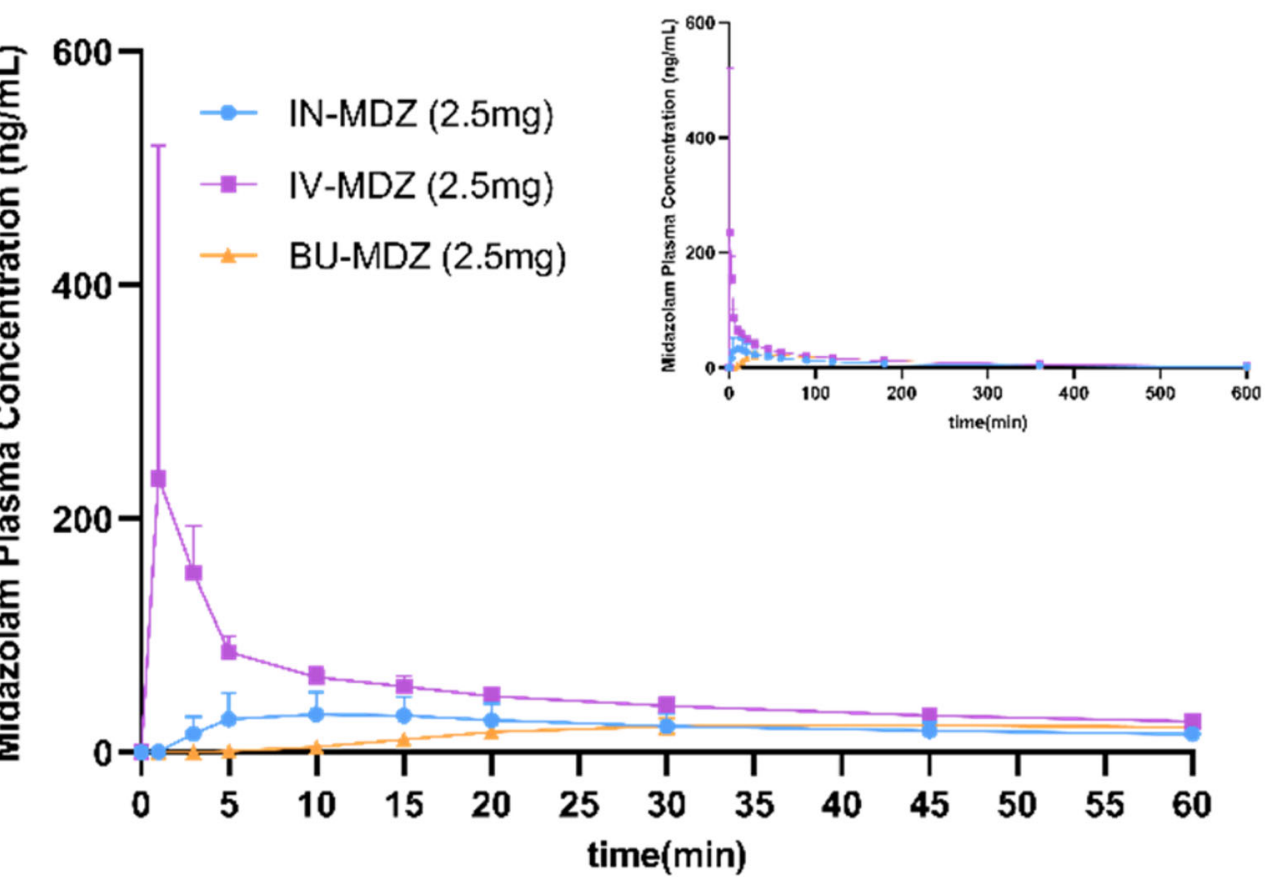

Fig. 2 Mean \pm SD plasma midazolam plasma concentration-time curves for the three treatments in 12 healthy subjects 


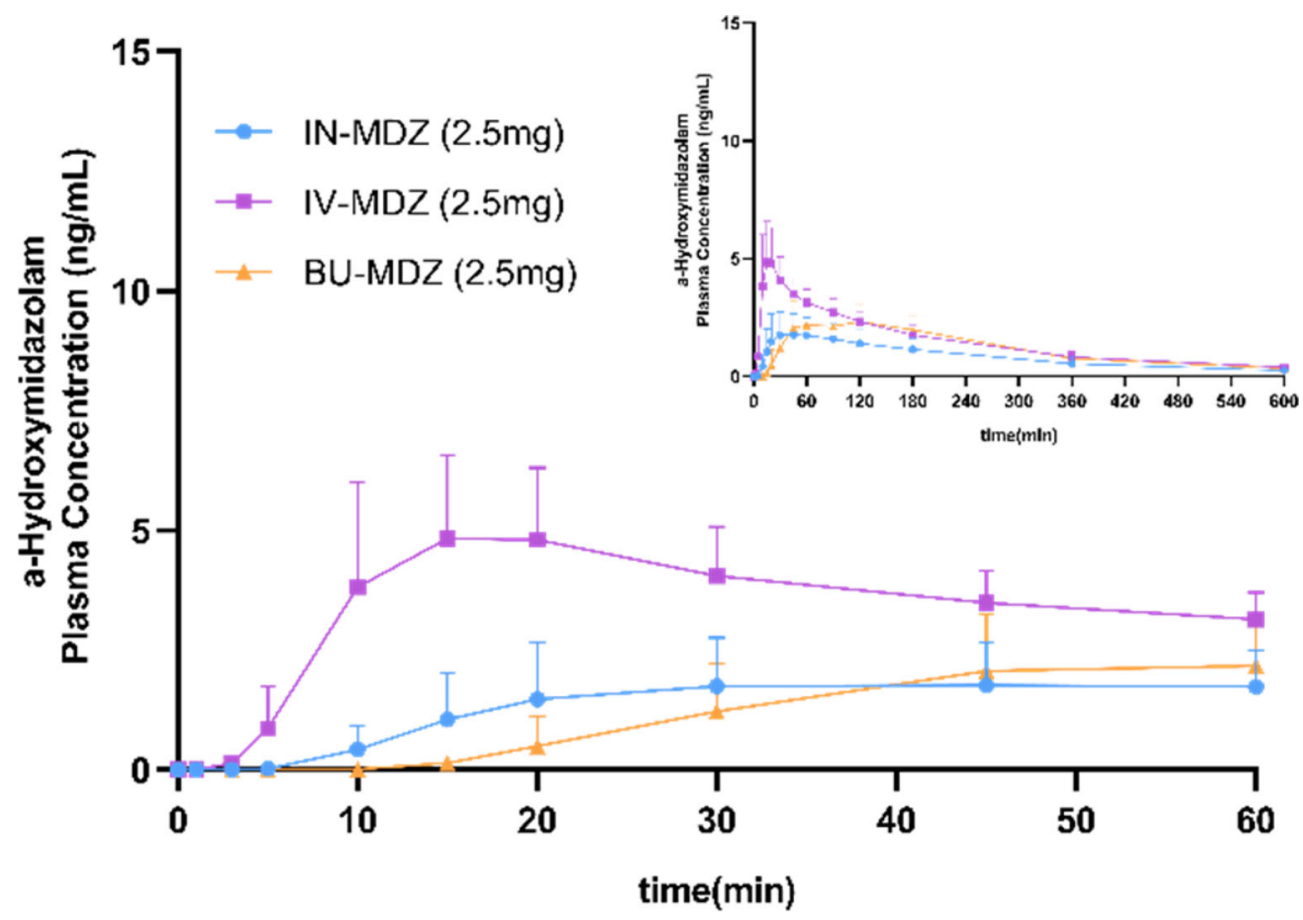

Fig. 3 Mean $\pm S D$-hydroxymidazolam plasma concentration-time curves for the three treatments in 12 healthy subjects

Table 1 Pharmacokinetic parameters of midazolam and 1-OH MDZ after the three treatments $(N=12)$

\begin{tabular}{|c|c|c|c|}
\hline \multirow[t]{2}{*}{ Parameters } & \multicolumn{3}{|l|}{ Treatments } \\
\hline & IN-MDZ $2.5 \mathrm{mg}$ & IV-MDZ $2.5 \mathrm{mg}$ & BC-MDZ $2.5 \mathrm{mg}$ \\
\hline \multicolumn{4}{|l|}{ Midazolam } \\
\hline $\mathrm{AUC}_{0-\infty}$, mean $(\mathrm{SD}), \mathrm{ng} \cdot \mathrm{h} / \mathrm{ml}$ & $77.20(31.98)$ & $139.94(27.52)$ & $95.80(20.87)$ \\
\hline $\mathrm{AUC}_{0-1 \mathrm{~h}}$, mean $(\mathrm{SD}), \mathrm{ng} \cdot \mathrm{h} / \mathrm{ml}$ & $22.44(9.94)$ & $51.79(11.73)$ & $16.84(4.32)$ \\
\hline$C_{\max }, \operatorname{mean}(\mathrm{SD}), \mathrm{ng} / \mathrm{ml}$ & $38.33(18.85)$ & $299.98(236.45)$ & $24.97(4.99)$ \\
\hline$T_{\max }$, median (range), $\mathrm{h}$ & $0.21(0.083-0.85)$ & $0.05(0.018-0.057)$ & $0.75(0.5-1.5)$ \\
\hline$t_{1 / 2}$, mean $(\mathrm{SD}), \mathrm{h}$ & $3.19(0.69)$ & $3.05(0.51)$ & $2.68(0.36)$ \\
\hline \multicolumn{4}{|l|}{$\alpha$-Hydroxymidazolam } \\
\hline $\mathrm{AUC}_{0-\infty}$, mean $(\mathrm{SD}), \mathrm{ng} \cdot \mathrm{h} / \mathrm{ml}$ & $9.50(3.99)$ & $16.37(3.47)$ & $13.18(4.28)$ \\
\hline $\mathrm{AUC}_{0-1 \mathrm{~h}}$, mean $(\mathrm{SD}), \mathrm{ng} \cdot \mathrm{h} / \mathrm{ml}$ & $1.33(0.74)$ & $3.48(0.89)$ & $1.12(0.63)$ \\
\hline$C_{\max }$, mean $(\mathrm{SD}), \mathrm{ng} / \mathrm{ml}$ & $2.12(1.10)$ & $5.39(1.93)$ & $2.76(1.03)$ \\
\hline$T_{\max }$, median (range), $\mathrm{h}$ & $0.75(0.333-1.501)$ & $0.29(0.168-0.751)$ & $2.00(0.501-3.011)$ \\
\hline$t_{1 / 2}$, mean $(\mathrm{SD}), \mathrm{h}$ & $3.17(0.48)$ & $3.06(0.48)$ & $2.71(0.53)$ \\
\hline
\end{tabular}

$A U C_{O-\infty}$ area under the concentration time curve from time 0 to infinity, $C_{\text {max }}$ maximum observed plasma concentration, $I N-M D Z$ intranasally administered midazolam, $I V-M D Z$ intravenously administered midazolam, $B C-M D Z$ buccally administered midazolam, $S D$ standard deviation, $T_{\max }$ time to maximum observed plasma concentration, $t_{1 / 2}$ terminal elimination half-life 
Table 2 Bioavailability of midazolam after the three treatments $(N=12)$

\begin{tabular}{llll}
\hline Drug & IN-MDZ 2.5 mg & IV-MDZ 2.5 mg & BC-MDZ 2.5 mg \\
\hline Absolute bioavailability, \% & 49.39 & 100 & 68.22 \\
Relative bioavailability, \% & 72.41 (IN-MDZ vs. BC-MDZ) & - & 100 \\
\hline
\end{tabular}

Absolute bioavailability: the amount of drug from a formulation that reached the systemic circulation relative to an intravenous dose

did not show bioequivalence; the absolute bioavailability of BC-MDZ was greater than that of IN-MDZ. The absolute bioavailability of INMDZ compared to BC-MDZ was $72.41 \%$. The comparison of main pharmacokinetic parameters including $C_{\max }, T_{\max }$, and $\mathrm{AUC}_{0-\infty}$ between the three the treatments is shown in Fig. 4; IN$\mathrm{MDZ}$ and $\mathrm{BC}-\mathrm{MDZ}$ resulted in comparable $\mathrm{AUC}_{0-\infty}$ and $C_{\max }$ values at $2.5 \mathrm{mg}$ but lower than IV-MDZ at $2.5 \mathrm{mg}$. At the same time, IN-MDZ demonstrated a more rapid time to peak midazolam concentration compared to BC-MDZ. As the effective time of the MDZ is very important for the control of epilepsy, early treatments would shorten the duration and help avoid adverse effects from prolonged seizure activity [16]. We also compared $\mathrm{AUC}_{0-0.5 \mathrm{~h}}, \mathrm{AUC}_{0-1 \mathrm{~h}}$, and $\mathrm{AUC}_{0-2 \mathrm{~h}}$ between the three treatments; the exposure of IV-MDZ was the largest from beginning to end, and the exposure of IN-MDZ was higher than BC-MDZ at $0-0.5 \mathrm{~h}$, but there was no difference between the other two periods (Fig. 5). In summary, although the same dose of $2.5 \mathrm{mg}$ of IN-MDZ and BC-MDZ did not show bioequivalence, the IN-MDZ reached peak concentration much faster than BC-MDZ.

\section{Safety and Tolerability}

Ten treatment emergent adverse events (TEAEs) were reported (Table 3). All TEAEs were considered mild, with most (20\%) considered probably related to the study drug. Overall, the drug-related TEAEs were elevation of alanine aminotransferase $(8.3 \%)$ and reduction of diastolic blood pressure (8.3\%). No serious adverse events (SAEs) or deaths were reported, and no TEAEs led to study discontinuation.

\section{DISCUSSION}

The results from this phase 1 study confirmed that midazolam is quickly and consistently absorbed by intranasal administration ( $T_{\max }$, $0.21 \mathrm{~h}$ vs. $0.75 \mathrm{~h}$ ), but with a relatively lower plasma $\mathrm{AUC}_{0-\infty}$ than buccal administration $\left(\mathrm{AUC}_{0-\infty}, 77.20\right.$ vs. $\left.95.90 \mathrm{ng} \cdot \mathrm{h} / \mathrm{ml}\right)$. Moreover, because the nasal mucosa is located near the brain, it is easier for drugs to directly enter the brain and obtain a higher concentration in the cerebrospinal fluid than in plasma [17].

It is well established that timely and rapid treatment for epileptic seizures is critical. Patients with epilepsy would suddenly lose consciousness during seizures, accompanied by screaming, urinary incontinence, tongue bite, etc. Acute repetitive or prolonged seizures are the most common neurological emergencies, which may rapidly progress to status epilepticus (SE), with a high mortality rate of $23 \%$ [16]. In addition, long-lasting seizures are more likely associated with poor outcomes, including neuronal death, hippocampal injury, and chronic epileptic seizures [16, 18]. Early treatments would shorten the duration and help avoid adverse effects from prolonged seizure activity [16]. Given the limitations of intravenous delivery in this specific scenario, which make it difficult for nonclinical caregivers to administer quickly and safely, alternative routes of antiepileptic drugs administration have been explored, e.g., oral [19], intranasal [17, 20], intramuscular [21], and buccal delivery [4, 22]. Children and adolescents with prolonged acute convulsive seizures occurring in community settings can be managed with BC-MDZ, owing to its demonstrated quicker and easier access than the intravenous route [23]. However, the buccal route of administration is often 

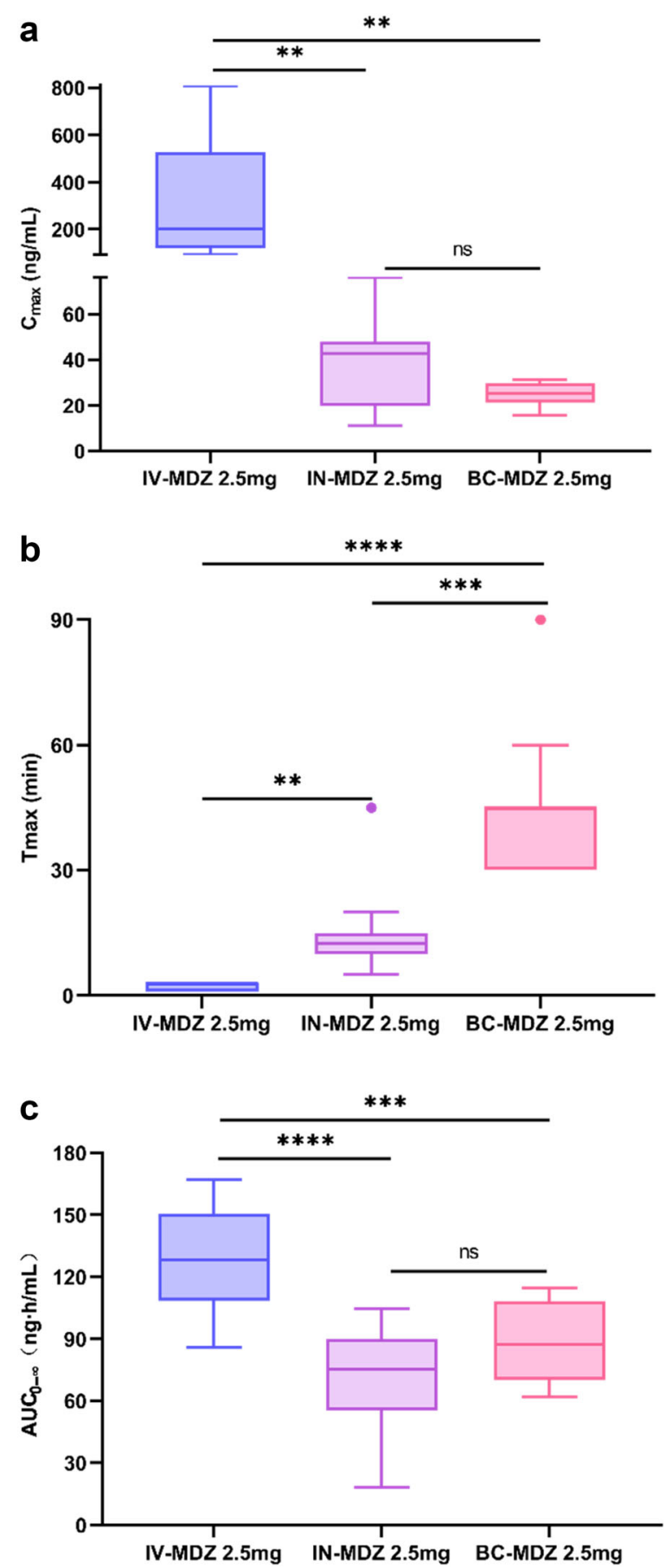

Fig. 4 Comparison of main pharmacokinetic parameters including a $C_{\max }$ (peak plasma concentration); b $T_{\max }$ (time to reach maximum plasma concentration); c $\mathrm{AUC}_{0-\infty}$ (area under the concentration time curve from time 0 to infinity) between the three treatments. All data presented as mean \pm SD. ns, not significant; ${ }^{*} P<0.05 ;{ }^{* *} P<0.01 ;{ }^{* * *} P<0.001 ;{ }^{* * * *} P<0.0001$
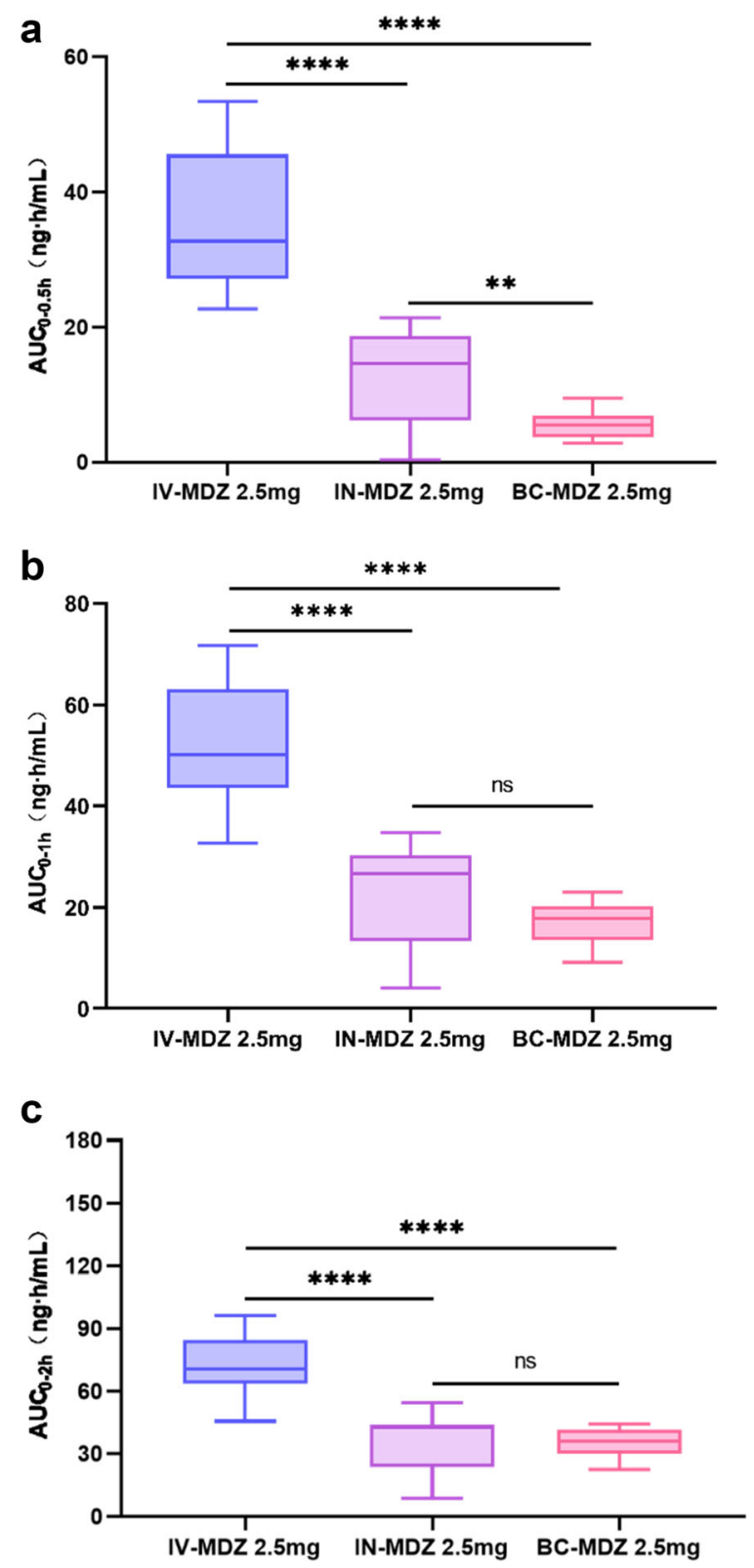

Fig. 5 Comparison of pharmacokinetic parameters including a $\mathrm{AUC}_{0-0.5 \mathrm{~h}}$ (area under the concentration time curve from time 0 to $0.5 \mathrm{~h}$ ); $\mathbf{b} \mathrm{AUC}_{0-1 \mathrm{~h}}$ (area under the concentration time curve from time 0-1h); c $\mathrm{AUC}_{0-2 \mathrm{~h}}$ (area under the concentration time curve from time 0 to $2 \mathrm{~h}$ ) between the three treatments. All data presented as mean \pm SD. ns, not significant; ${ }^{*} P<0.05 ;{ }^{* *} P<0.01$; ${ }^{* * *} P<0.001 ;{ }^{* * * *} P<0.0001$

hampered by jaw clenching, hypersalivation, or uncontrolled swallowing [11] and the absorption of midazolam was unpredictable in this 
Table 3 Incidence of TEAEs in any treatment group $(N=12)$

\begin{tabular}{llll}
\hline Drug & IN-MDZ 2.5 mg & IV-MDZ 2.5 mg & BC-MDZ 2.5 mg \\
\hline TEAE, $n$ (\%) & $2(16.7)$ & $4(33.3)$ & $4(33.3)$ \\
Elevated blood triglycerides & 0 & $2(16.7)$ & $1(8.3)$ \\
Elevated pulse in the arm & $1(8.3)$ & 0 & $1(8.3)$ \\
Elevation of alanine aminotransferase & 0 & $1(8.3)$ & 0 \\
Diastolic blood pressure decrease & 0 & 0 & $1(8.3)$ \\
Elevated blood cholesterol & 0 & $1(8.3)$ & 0 \\
Elevated serum uric acid & 0 & 0 & $1(8.3)$ \\
Injecting fear & $1(8.3)$ & 0 & 0 \\
Blister & 0 & 0 & $1(8.3)$ \\
Mouth ulcers & 0 & $1(8.3)$ & 0 \\
ADR, $n$ (\%) & 0 & $1(8.3)$ & $1(8.3)$ \\
Elevation of ALT & 0 & $1(8.3)$ & 0 \\
Reduction of DBP & 0 & 0 & $1(8.3)$ \\
SAE & 0 & 0 & 0 \\
SADR & 0 & 0 & 0 \\
\hline
\end{tabular}

$M D Z$ midazolam, $I N$ intranasal, $I V$ intravenous, TEAE treatment emergent adverse event, $A D R$ adverse drug reaction, $A L T$ alanine aminotransferase, $D B P$ diastolic blood pressure, $S A E$ serious adverse event, $S A D R$ serious adverse drug reaction

situation [10], although the research is carried out in an ideal state of healthy volunteers without showing the real state of patients with epilepsy. Our study showed that IN-MDZ could be a preferable alternative to $\mathrm{BC}-\mathrm{MDZ}$ for the treatment of prolonged acute convulsive seizures in children and adolescents.

Regarding details related to midazolam use by intranasal administration, the literature reported that intranasal midazolam was administrated by diluting an intravenous solution to $0.2 \mathrm{mg} / \mathrm{kg}$, followed by either using a needleless syringe or dripping the solution into the nose $[24,25]$. In fact, intravenous solutions may be inappropriate for intranasal administration, because they lack optimization of the preparation procedures, e.g., modifications of drug solutions, optimum concentration and dosage, and/or dosing volume [26, 27]. Moreover, although seven studies researched the intranasal administration of midazolam, none reported whether atomizers were attached, but used syringes [25, 28, 29], nasal dropper [30], or omitted their administration methods altogether [24, 31, 32]. Meanwhile, commercially available midazolam for atomized administration is produced with relatively low concentrations, which may limit its intranasal use. The $T_{\max }$ and $t_{1 / 2}$ of IN-MDZ after a single dose of $2.5 \mathrm{mg}$ in our study was consistent with the published data ( $T_{\max }, 12.6 \mathrm{~min}$ vs. $14.5-15.7 \mathrm{~min} ; \quad t_{1 / 2}, \quad 3.19 \mathrm{~h}$ vs. $5.7-8.1 \mathrm{~h}$, respectively), and the $\mathrm{AUC}_{0_{-} \infty}$ and $C_{\max }$ for IN$\mathrm{MDZ} 2.5 \mathrm{mg}$ were slightly higher $\left(\mathrm{AUC}_{0-\infty}\right.$, $77.20 \mathrm{ng} \cdot \mathrm{h} / \mathrm{ml} \quad$ vs. $\quad 38.4-70 \mathrm{ng} \cdot \mathrm{h} / \mathrm{ml} ; \quad C_{\max }$, $38.33 \mathrm{ng} / \mathrm{ml}$ vs. $22.5-35.1 \mathrm{ng} / \mathrm{ml}$, respectively) [33, 34].

Most concentrated intranasal solutions have an acidic $\mathrm{pH}$, which can cause nasal irritation, discomfort, and less reliable absorption of midazolam $[9,14,35,36]$. The solubility of $\mathrm{MDZ}$ was greatly increased by decreasing the $\mathrm{pH}$ 
from near-physiological values to $\mathrm{pH}$ 3.3. Concentrated formulations with a $\mathrm{pH}$ value of 4.0-5.0 have been prepared that induce a lesser degree of nasal irritation, but they still cause other adverse effects such as watery eyes and have an unpleasant taste [37]. Unexpectedly, no volunteers experienced nasal discomfort after intranasal administration in our study. Some reasons may explain this situation: it is worth noting that a significant improvement in our study is that we developed intranasal solution of midazolam with a $\mathrm{pH}$ value of 6.0 for the first time. In the trial, the participants were given only a single low dose of midazolam.

Of course, we only studied the pharmacokinetic and safety of a single dose of midazolam in this trial. We recommended that different doses of midazolam nasal spray should be studied to further study the pharmacodynamic characteristic of midazolam nasal spray.

\section{CONCLUSIONS}

IN-MDZ is a new, intranasal formulation of MDZ optimized for single-dose delivery, although the absolute bioavailability of BCMDZ was greater than IN-MDZ. IN-MDZ may overcome the deficiency of IV-MDZ and BUMDZ and can be easily and quickly administered to children and adolescents with prolonged acute convulsive seizures by a caregiver.

\section{ACKNOWLEDGEMENTS}

The authors thank the subjects who participated in this clinical trial, study coordinators, and support staff.

Funding. The study and the journal's Rapid Service Fee was supported by the Yichang Renfu Pharmaceutical Co., Ltd., the National Major new drug creation project of China (no. 2020ZX09201010), and Hunan Provincial Natural Science Foundation of China (2021JJ31022, 2020JJ5852).

Authorship. All named authors meet the International Committee of Medical Journal
Editors (ICMJE) criteria for authorship for this article, take responsibility for the integrity of the work as a whole, and have given their approval for this version to be published.

Author's Contributions. All authors contributed to drafting this manuscript by providing critical revisions and important intellectual content, and all approved the final version for submission. HW and JH were involved in the design of the study and analysis of data. LEL, MZ, MFM, XZ were responsible for the project implementation. SY, XFZ, XYY, CC, CZ, KMD were involved in the analysis of blood and urine samples. GPY and SYW were the principal investigators.

Disclosures. Li-e Li, Min Zhang, Miao-fu Mao, Xiang Zhou were employees of Yichang Renfu Pharmaceutical Co. Hui Wang, Jie Huang, Shuang Yang, Xing-fei Zhang, Xiaoyan Yang, Chang Cui, Chan Zou, Kai-ming Duan, Sai-ying Wang, Guo-ping Yang have nothing to disclose.

Compliance with Ethics Guidelines. All pertinent study documents were reviewed, and the study protocol approved by the Institutional Review Board of the Third Xiangya Hospital of Central South University (application number 2019116). The study was conducted in accordance with the Declaration of Helsinki and Good Clinical Practice guidelines. All subjects provided written informed consent and the study was registered at the Chinese Clinical Trial Registry [http://www.chictr.org. cn] (No. ChiCTR1900025071).

Data Availability. The datasets generated during and/or analyzed during the current study are available from the corresponding author on reasonable request.

Open Access. This article is licensed under a Creative Commons Attribution-NonCommercial 4.0 International License, which permits any non-commercial use, sharing, adaptation, distribution and reproduction in any medium or format, as long as you give appropriate credit to the original author(s) and the source, provide 
a link to the Creative Commons licence, and indicate if changes were made. The images or other third party material in this article are included in the article's Creative Commons licence, unless indicated otherwise in a credit line to the material. If material is not included in the article's Creative Commons licence and your intended use is not permitted by statutory regulation or exceeds the permitted use, you will need to obtain permission directly from the copyright holder. To view a copy of this licence, visit http://creativecommons.org/licenses/by$\mathrm{nc} / 4.0 /$.

\section{REFERENCES}

1. Beghi E. The epidemiology of epilepsy. Neuroepidemiology. 2020;54(2):185-91.

2. Zack MM, Kobau R. National and state estimates of the numbers of adults and children with active epilepsy-United States, 2015. MMWR Morb Mortal Wkly Rep. 2017;66(31):821-5.

3. Ding D, Zhou D, Sander JW, Wang W, Li S, Hong Z. Epilepsy in China: major progress in the past two decades. Lancet Neurol. 2021;20(4):316-26.

4. Scott LJ, Lyseng-Williamson KA, Garnock-Jones KP. Oromucosal midazolam: a guide to its use in paediatric patients with prolonged acute convulsive seizures. CNS Drugs. 2012;26(10):893-7.

5. Penovich PE, Buelow J, Steinberg K, Sirven J, Wheless J. Burden of seizure clusters on patients with epilepsy and caregivers: survey of patient, caregiver, and clinician perspectives. Neurologist. 2017;22(6): 207-14.

6. Kapoor M, Cloyd JC, Siegel RA. A review of intranasal formulations for the treatment of seizure emergencies. J Control Release. 2016;237:147-59.

7. Shtull-Leber E, Silbergleit R, Meurer WJ. Pre-hospital midazolam for benzodiazepine-treated seizures before and after the rapid anticonvulsant medication prior to arrival trial: a national observational cohort study. PLoS ONE. 2017;12(3):e0173539.

8. Nunes VD, Sawyer L, Neilson J, Sarri G, Cross JH. Diagnosis and management of the epilepsies in adults and children: summary of updated NICE guidance. BMJ. 2012;344:e281.
9. Wheless JW. A critical evaluation of midazolam nasal spray for the treatment of patients with seizure clusters. Expert Rev Neurother. 2021:21: 1195-1205.

10. Mula M. New non-intravenous routes for benzodiazepines in epilepsy: a clinician perspective. CNS Drugs. 2017;31(1):11-7.

11. Rey E, Treluyer JM, Pons G. Pharmacokinetic optimization of benzodiazepine therapy for acute seizures. Focus on delivery routes. Clin Pharmacokinet. 1999;36(6):409-24.

12. Sutter R, Kaplan PW. Transnasal revolution? The promise of midazolam spray to prevent seizure clusters. CNS Drugs. 2020;34(5):555-7.

13. Brigo F, Nardone R, Tezzon F, Trinka E. A common reference-based indirect comparison meta-analysis of buccal versus intranasal midazolam for early status epilepticus. CNS Drugs. 2015;29(9):741-57.

14. Mula M. The safety and tolerability of intranasal midazolam in epilepsy. Expert Rev Neurother. 2014;14(7):735-40.

15. Hyland $\mathrm{R}$, Osborne $\mathrm{T}$, Payne $\mathrm{A}$, et al. In vitro and in vivo glucuronidation of midazolam in humans. Br J Clin Pharmacol. 2009;67(4):445-54.

16. Naylor DE. Treating acute seizures with benzodiazepines: does seizure duration matter? Epileptic Disord. 2014;16(s1):S69-83.

17. Kälviäinen R. Intranasal therapies for acute seizures. Epilepsy Behav. 2015;49:303-6.

18. Shinnar S, Hesdorffer DC, Nordli DR Jr, et al. Phenomenology of prolonged febrile seizures: results of the FEBSTAT study. Neurology. 2008;71(3):170-6.

19. Backman JT, Olkkola KT, Ojala M, Laaksovirta H, Neuvonen PJ. Concentrations and effects of oral midazolam are greatly reduced in patients treated with carbamazepine or phenytoin. Epilepsia. 1996;37(3):253-7.

20. Ivaturi VD, Riss JR, Kriel RL, Cloyd JC. Pharmacokinetics and tolerability of intranasal diazepam and midazolam in healthy adult volunteers. Acta Neurol Scand. 2009;120(5):353-7.

21. Silbergleit R, Durkalski V, Lowenstein D, et al. Intramuscular versus intravenous therapy for prehospital status epilepticus. N Engl J Med. 2012;366(7):591-600.

22. Grass J, Rose P, Burhenne J, Blank A, Haefeli WE, Mikus G. Absolute bioavailability of microdosed midazolam after buccal administration is 
dependent on buccal exposure time. J Clin Pharmacol. 2021;61(4):472-9.

23. Glauser T, Shinnar S, Gloss D, et al. Evidence-based guideline: treatment of convulsive status epilepticus in children and adults: report of the guideline committee of the American Epilepsy Society. Epilepsy Curr. 2016;16(1):48-61.

24. Javadzadeh M, Sheibani K, Hashemieh M, Saneifard H. Intranasal midazolam compared with intravenous diazepam in patients suffering from acute seizure: a randomized clinical trial. Iran J Pediatr. 2012;22(1):1-8.

25. Lahat E, Goldman M, Barr J, Bistritzer T, Berkovitch M. Comparison of intranasal midazolam with intravenous diazepam for treating febrile seizures in children: prospective randomised study. BMJ. 2000;321(7253):83-6.

26. Wermeling DP. Intranasal delivery of antiepileptic medications for treatment of seizures. Neurotherapeutics. 2009;6(2):352-8.

27. Pires A, Fortuna A, Alves G, Falcao A. Intranasal drug delivery: how, why and what for? J Pharm Pharm Sci. 2009;12(3):288-311.

28. Mittal P, Manohar R, Rawat AK. Comparative study of intranasal midazolam and intravenous diazepam sedation for procedures and seizures. Indian J Pediatr. 2006;73(11):975-8.

29. Mahmoudian T, Zadeh MM. Comparison of intranasal midazolam with intravenous diazepam for treating acute seizures in children. Epilepsy Behav. 2004;5(2):253-5.

30. Bhattacharyya M, Kalra V, Gulati S. Intranasal midazolam vs rectal diazepam in acute childhood seizures. Pediatr Neurol. 2006;34(5):355-9.
31. Holsti M, Dudley N, Schunk J, et al. Intranasal midazolam vs rectal diazepam for the home treatment of acute seizures in pediatric patients with epilepsy. Arch Pediatr Adolesc Med. 2010;164(8): 747-53.

32. Fisgin T, Gurer Y, Tezic T, et al. Effects of intranasal midazolam and rectal diazepam on acute convulsions in children: prospective randomized study. J Child Neurol. 2002;17(2):123-6.

33. Bouw MR, Chung SS, Gidal B, et al. Clinical pharmacokinetic and pharmacodynamic profile of midazolam nasal spray. Epilepsy Res. 2021;171: 106567.

34. Berg AK, Myrvik MJ, Van Ess PJ. Pharmacokinetics, pharmacodynamics, and tolerability of USL261, midazolam nasal spray: randomized study in healthy geriatric and non-geriatric adults. Epilepsy Behav. 2017;71(Pt A):51-9.

35. Kay L, Reif PS, Belke M, et al. Intranasal midazolam during presurgical epilepsy monitoring is well tolerated, delays seizure recurrence, and protects from generalized tonic-clonic seizures. Epilepsia. 2015;56(9):1408-14.

36. von Blomberg A, Kay L, Knake S, et al. Efficacy, tolerability, and safety of concentrated intranasal midazolam spray as emergency medication in epilepsy patients during video-EEG monitoring. CNS Drugs. 2020;34(5):545-53.

37. Loftsson T, Gudmundsdottir H, Sigurjonsdottir JF, et al. Cyclodextrin solubilization of benzodiazepines: formulation of midazolam nasal spray. Int J Pharm. 2001;212(1):29-40. 